\title{
Dislocación y borderland: Una mirada oblicua desde el feminismo descolonial al entramado migración, régimen heterosexual, (pos) colonialidad y globalización ${ }^{1}$
}

Camila Esguerra Muelle ${ }^{2}$

Universidad Nacional de Colombia, Bogotá, Colombia ${ }^{3}$ camiesguerra@gmail.com

Recibido: 8 de octubre de 2013

Aceptado: 23 de enero de 2014

Artículo de Reflexión derivado de la investigación de campo realizada durante 2008, 2009 y 2010 en Madrid para la tesina de Maestría en Estudios de Género y Etnicidad de la Universidad de Utrecht, Holanda, en calidad de becaria GEMMA-Erasmus Mundus. El presente artículo da cuenta de las principales preguntas y reflexiones constitutivas de dicha investigación desde una perspectiva crítica y analítica.

2 Maestra en Género y Etnicidad de la Universidad de Utrecht, Holanda y de la Universidad de Oviedo, España. Estudiante del Doctorado en Humanidades de la Universidad Carlos III de Madrid.

3 Profesora e investigadora de la Escuela de Estudios de Género y de la Maestría en Estudios Culturales.

Documento accesible en línea desde la siguiente dirección: http://revistas.javeriana.edu.co

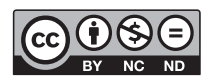




\title{
Dislocación y borderland: Una mirada oblicua desde el feminismo descolonial al entramado migración, régimen heterosexual, (pos)colonialidad y globalización
}

\section{Resumen}

Este artículo es producto de mi investigación de tesina para optar por el título de Maestra en Género y Enticidad de la Universidad de Utrecht, que implicó hacer investigación, acción, participación y construir entrevistas con enfoque biográfico, analizando la manera en que las lesbianas latinoamericanas o mujeres que han vivido experiencias homoeróticas ${ }^{4}$ están situadas a lo largo de sus trayectorias de vida: a) dentro de las redes de poder que operan tanto en sus países de origen como en España (biopolítica), asi como en una serie de complejas relaciones globales (geopolítica); b) dentro de determinados colectivos (micropolítica) y; c) en sus relaciones personales o de pareja (micropolítica). Me propuse con esta investigación poner en juego una mirada heterárquica e interseccional.

Palabras clave: heterosexualidad obligatoria; colonialidad; sexualidad; migración; globalización; lesbianas

\section{Displacement and Borderland: An Oblique View from the Decolonial Feminism to the Scheme Migration, Heterosexual Regime, (Post)colonialism and Globalization}

\begin{abstract}
This article is the result of my research thesis to qualify for the title of Master in Gender and Ethnicity from the University of Utrecht, which entailed doing research, action, participation, and building interviews with a biographical approach, analyzing the way in which Latin American lesbian or women who have lived homoerotic experiences are situated along their paths of life: a) within the networks of power that operate both in their countries of origin and in Spain (biopolitics), as well as in a series of complex global relations ( geopolitics); b) within certain collectives (micropolitics) and; c) in their personal or couple relationships (micropolitics). I set out in this research to employ a heterarchical and intersectional look.
\end{abstract}

Keywords: compulsory heterosexuality; coloniality; sexuality; migration; globalization; lesbians

\section{Deslocação e borderland: Olhar obliquo desde o feminismo descolonial ao entretecido migração, regimen heterossexual, (pós)colonialidade e globalização}

\section{Resumo}

Este artigo é produto da minha tesina para obter o título de Mestra em Gênero e Enticidade da Universidade de Utrecht, que envolveu fazer pesquisa-ação-participação e construir entrevistas com enfoque biográfico, analisando a maneira em que as lésbicas latino-americanas ou mulheres que têm vivido experiências homoeróticas estão situadas ao longo das suas trajetórias de vida: a) no âmbito das redes de poder que operam tanto nos seus países de origem como na Espanha (biopolítica), assim como em uma série de complexas relações globais (geopolítica); b) dentro de determinados coletivos (micropolítica) e; c) nas relações pessoais ou de casal (micropolítica). Propus-me nesta pesquisa colocar em jogo um olhar heterárquico e interseccional.

Palavras-chave: heterossexualidade obrigatória; colonialidade; sexualidade; migração; globalização; lésbicas

4 Hablaré tanto de mujeres con experiencias homoeróticas como de mujeres lesbianas porque algunas de ellas no se reconocen como lesbianas, incluso algunas de ellas usan otras categorias identitarias, como gay, para autonombrarse, sin embargo, todas las entrevistadas han tenido experiencias homoeróticas o que uno podría definir como parte del llamado "continnum lésbico" (Rich, 1984) o se han apartado en alguna medida del régimen heterosexual. 


\section{Heterosexualidad obligatoria, (pos)colonialidad y globalización}

En el presente artículo, busco hacer una aproximación para comprender cómo los niveles de poder micro (micropolítica), meso (biopolítica) y macro (geopolitica) atraviesan las vidas de mujeres que han tenido que enfrentar, como lesbianas o como mujeres con experiencias homoeróticas y como migrantes, tres grandes estructuras politicas: la globalización, la colonialidad y la heterosexualidad obligatoria.

En este sentido, creo necesario utilizar una perspectiva heterárquica (Castro-Gómez, 2002, p. 2). Aunque Castro-Gómez (2002, pp. 11-22) critica los contenidos eurocéntricos de la obra de Foucault, también señala cómo acertadamente, la analítica foucaultiana del poder propone diferentes niveles (micro: la construcción de sujeto y las tecnologias del ser; meso: uso estatal de la biopolítica; y macro: relaciones estatales e interestatales y tecnologías del poder situadas en el panorama geopolitico) que se articulan en una cadena, dentro de la cual ninguno guarda una relación jerárquica con otro y en donde cada uno de esos niveles de poder se intersecta de forma parcial y temporal con los otros. De esta manera, una aproximación heterárquica precisa tomar distancia de la noción jerárquica marxista "Sistema mundo" (Wallerstein, 1974), aplicada como categoría explicativa total.

Al mismo tiempo, propongo una aproximación interseccional para la que los sistemas racialización/racismo, sexo/género, etnia/etnicidad, edad/sistema etario, clase/clasismo son categorías obligatorias de análisis que deben ser vistas en el contexto de grandes sistemas o circunstancias histórico-culturales como la (pos)colonialidad, la globalización y la institucionalización de la heterosexualidad.

Para acercarme de una manera más tangible a esta cuestión, al final focalizaré la discusión en un aspecto concreto: entender de qué manera las latinoamericanas migrantes, en particular lesbianas o mujeres con experiencias homoeróticas, han sido resituadas en la división sexual internacional del trabajo, que de manera paulatina y simultanea, ha feminizado la fuerza de trabajo y la pobreza, en particular dentro las llamadas cadenas globales del cuidado, y la generación de plusvalía emocional como mecanismos para atender el déficit de cuidado (Hochschild, 2000).

Con el propósito de dar sustento a la presente discusión en experiencias de mujeres, haré uso de la investigación cualitativa que llevé a cabo para la elaboración de mi tesina de Maestría que consistió en la realización de entrevistas semiestructuradas con enfoque biográfico 
realizadas a ocho mujeres migrantes, lesbianas o con experiencias homoeróticas -como señalé anteriormente hago esta distinción dado que varias de ellas no se autodenominan como lesbianas- y observación participante durante aproximadamente un año en Madrid.

Mi planteamiento central es que las circunstancias que caracterizan el panorama de globalización de lesbofobia fundadas en la institución de la heterosexualidad obligatoria; de xenofobia y racismo, producto en buena parte de las relaciones de colonialidad y postcolonialidad, y los llamados déficit de cuidado y fuga de cuidado (Hochschild, 2000) entroncados a fenómenos como la globalización, sitúan a las latinoamericanas migrantes en general y a las lesbianas o a las mujeres con experiencias homoeróticas en particular, en un espacio social en entredicho, en suspensión.

Considero que la heterosexualidad obligatoria-concebida como una institución política y económica y no como un régimen que solo alude a la orientación del deseo (Rich, 1984) - es uno de los factores que influyen en la decisión de estas mujeres de emigrar o de permanecer en el país de acogida y que pocas veces ha sido tenido en cuenta en el análisis de las migraciones, sobre todo cuando se da por sentado que las migraciones actuales son un fenómeno con una sola causa atribuible a cuestiones meramente económicas o cuando se deja de lado que los sistemas sexo género -y en particular el sistema de género moderno colonial (Lugones, 2007) y la heterosexualidad obligatoria como constitutiva de este último- tienen su propia economía intrínseca y son tan complejos y estructurantes como los sistemas económicos, si es que una disección de este tipo es posible.

En consecuencia, el análisis que se hace de la migración, termina por despolitizarse y no complejizarse de manera suficiente. En este punto es importante señalar que en los países de origen opera un régimen hegemónico que es el sistema género moderno colonial (Lugones, 2007) que se caracteriza por ordenar el género y la sexualidad a partir de las operaciones coloniales sobre cuatro premisas principales: el binarismo de género (cisgenerismo ${ }^{5}$ prescriptivo), el dimorfismo sexual, el androcentrismo y la heterosexualidad como norma, lo que termina por exceptuar otros sistemas sexo género que pueden pervivir y convivir de manera simultánea y que no cumplen con todas estas reglas estructurantes.

Se refiere a la idea de que hay una correspondencia natural entre la asignación de sexo mujer, género femenino y la asignación sexual hombre y género masculino. 
Por otra parte, la colonialidad, se manifiesta, según pude ver, particularmente en formas de xenofobia y racismo pero también mediante la operación de la heterosexualidad como régimen y atraviesa toda la experiencia migratoria de estas mujeres; y por último, la globalización se hace presente de manera muy clara en la reinserción dentro de las cadenas de cuidado, en las que por demás, muchas de estas mujeres están inmersas desde sus países de origen y que también constituyen una de las formas en que la heterosexualidad obligatoria opera en la vida de todas las mujeres. Las cadenas de cuidado son una manifestación que combina los niveles micropolítico (sujeción del sujeto), biopolitico (políticas de los estados de bienestar caracterizados paradójicamente por un déficit de cuidado o de Estados débiles que proveen cuidadoras) y geopolítico (relación desbalanceada entre Estados) del poder.

En relación con cuestiones como la poscolonialidad, la heterosexualidad obligatoria y la globalización, España combina cinco importantes pero contradictorias condiciones que podrian inicialmente explicar que este país sea, para mujeres latinoamericanas migrantes, uno de los principales destinos en Europa: 1) el hecho de ser un pais hispanoparlante, como lo son la mayoria de latinoamericanos y la sensación de unidad cultural, lo que denota una relación poscolonial; 2) las politicas ${ }^{6}$ comparativamente más favorables a la migración latinoamericana que podrian interpretarse como una forma de reconocimiento por parte de España de su pasado colonial; 3) los muy relativos avances logrados en las politicas dirigidas a las mujeres; 4) los adelantos legales para parejas del mismo sexo, aunque la lesbofobia y la homofobia persistan en un alto grado dentro de la sociedad española y el derecho comparativo en realidad no permita una homologación de estos avances en otros países (véase Waaldijk, 2004); 5) el desplazamiento de la economía del cuidado hacia la población inmigrante femenina, que se ha dado gracias a cierta prosperidad económica alcanzada en España a partir de la década de 1980 (Folgueiras, 2005, p. 33 y 47). No obstante, cada una de estas condiciones mencionadas merece ser matizada.

1) Aunque en España estas mujeres encuentran un ambiente lingüístico relativamente amigable, pude constatar en las entrevistas que, aunque de manera sutil, se presentan algunas luchas alrededor de, por llamarlo así, el uso autorizado del español. En este

Orden del 13 de enero de 1989; Ley5/1984; artículo 22 de la Ley 36/2002 que reforma el Código Civil Español, entre otras. 
discurso tácito perviven aún vestigios de colonialidad. Sin embargo, las reacciones reportadas por todas las entrevistadas fueron siempre de resistencia lingüística, es decir, de descolonización.

Por otra parte, en España hay diversas manifestaciones de xenofobia sutil o explícita que se combina con formas de racismo. Desde mi punto de vista, resulta revelador que en el uso común, en España se confundan los significados de las palabras xenofobia y racismo. En general se llama racismo a cualquier forma de xenofobia, como si mediante algún mecanismo oculto se racializara y ubicara étnicamente a las naciones o grupos de extranjeros que luego son objeto del odio social o de su otra cara, una especie de compasión exotizante.

Durante el trabajo de campo en Madrid, pude observar que hay una distinción generalizada en el uso de las palabras inmigrantes y extranjeros: Mientras el vocablo inmigrante implica un estatus bajo y se usa para referirse principalmente a extranjeros de origen latinoamericano, árabe, africano y del este de Europa ${ }^{7}$, la palabra extranjero se usa para designar a inmigrantes de Europa occidental y de EEUU (véase Folgueiras, 2005, pp. 49-54). Sin embargo, es necesario aclarar que tal distinción no solo conlleva aspectos de segregación étnico-racial, sino también de clase.

Por lo tanto, esta ilusión de unidad iberoamericana funciona solo en el contexto de ciertos discursos que buscan por parte de ambas partes, no reconocer la relación de colonialidad que actualmente existe entre España y Latinoamérica hispanoparlante y parte del Caribe.

2) En cuanto a las políticas migratorias, hay que subrayar que estas han ido cambiando desde la promulgación de la llamada Directiva de la vergüenza $a^{8}$ y aún más, con la reforma de la ley de migración española que entró en vigencia el 10 de julio de $2009^{9}$. Esta nueva regulación no solo fomenta una atmosfera cultural propicia para la xenofobia, sino que a la vez profundiza la penalización contra los migrantes "sin papeles" y contra las y los españoles que intenten

7 No obstante el INE (Instituto Nacional de Estadísticas) define inmigrante como "una persona de la vivienda [hogar en España] que ha nacido en el extranjero, es mayor de 15 años y vive en España (o tiene intención de hacerlo) desde hace un año o más tiempo. (Se excluye el caso de españoles de nacimiento nacidos fuera de España que en el año de llegada a España tenían menos de 2 años)" (INE, 2009).

8 P6_TA-PROV(2008)0293.

9 Real Decreto 1162/2009 que enmienda la Ley Orgánica 4/ 2000 relativa a los derechos y libertades de extranjeros en España y a su integración social, aprobada mediante el Decreto Real 2393/2004. 
ayudarlos. Por otra parte, este clima xenofóbico se ha intensificado con la crisis económica y financiera que inició en 2010, ciclo del capitalismo que suele afectar los comportamientos migratorios y aquellos proferidos hacia las y los migrantes.

3) Aunque hay una serie de avances innegables en materia de políticas dirigidas a las mujeres y en las llamadas políticas de género, es importante señalar que en muchas ocasiones estas politicas han sido cuestionadas por los propios movimientos feministas en España, dentro de los cuales se encuentran amplios sectores de mujeres migrantes. El tema de politicas dirigidas hacia las mujeres es un asunto muy amplio sobre el que, para efectos del tema que estoy tratando, solo quisiera resaltar dos cuestiones. Las politicas dirigidas a las mujeres en muchas ocasiones no parten de un análisis profundo de la heterosexualidad obligatoria como institución. En estas políticas tampoco se tratan de manera estructural asuntos como la feminización de la migración y las condiciones de dicha migración. España tiene uno de los estatutos laborales más inequitativos con lo que llama en masculino los empleos de servicio doméstico, que hay que recordar dada la operación de cadenas globales del cuidado, son en su mayoría mujeres migrantes.

4) El reconocimiento de derechos de las parejas del mismo sexo tiene efectos contradictorios para las inmigrantes lesbianas o con experiencias homoeróticas en España. Por un lado representa la posibilidad de reconocimiento de parejas transnacionales, pero por otro lado instala la sensación de que la pelea está ganada y hace que se omita la discusión por el reconocimiento de los derechos individuales y colectivos de personas no heterosexuales.

A propósito de este tema, según dos de las mujeres entrevistadas, Patricia y Milena, las migrantes latinoamericanas que exceden la norma de la heterosexualidad obligatoria pueden ser vistas por algunas mujeres españolas como excesivamente demandantes en términos emocionales en tanto no tienen el soporte de sus familias y a la vez como personas interesadas en buscar en una relación amorosa, una vía de regularización en España.

En conexión con esta idea, Jules Falquet (2006, p. 59) afirma que este tipo de políticas estatales puede conducir a las mujeres a un nuevo tipo de prostitución internacional, dado que el matrimonio de parejas del mismo sexo, sería visto por las migrantes como una nueva forma para obtener papeles. En relación con el asunto, 
el Grup de Lesbianes Feministes de Barcelona reclama: "nosotras tenemos que ir más allá del matrimonio y la familia, dando validez social a otro tipo de relaciones erótico-afectivas, de solidaridad, convivencia y crianza de los niños" (Pichardo, 2004, p. 171). Esta postura es compartida por los movimientos feministas más autónomos en América Latina y el mundo.

En el análisis de Falquet (2006, pp. 56-57, 60) sobre los arreglos emocionales, sexuales y económicos entre lesbianas, hecho desde una perspectiva internacionalista y materialista como ella misma aclara, la autora delata cómo a través de la globalización neoliberal se impone la familia neo-nuclear (re)compuesta de y alrededor de individuos del mismo sexo, que no son autosuficientes ni material ni emocionalmente. Este modelo, junto con la hostilidad lesbofóbica, según la autora, va en detrimento de la autonomía de las mujeres y de su fortalecimiento como colectivo (Esguerra, 2009).

5) Sobre el desplazamiento de la economía del cuidado, la última de las condiciones favorables a la migración latinoamericana hacia España que señalaba anteriormente, me centraré en el último apartado de este ensayo con el fin de recoger la discusión propuesta. Esta elección responde a razones prácticas, pues en el fenómeno de las cadenas globales de cuidado es posible ver las trazas que la globalización, la colonialidad y la heterosexualidad obligatoria dejan en la vida de las mujeres.

Por otra parte, es claro que en los países de origen, imbricados en relaciones de colonialidad, operan los sistemas de raza/ racialización/racismo; clase y el sistema género moderno colonial (Lugones, 2007) estructurado en gran medida sobre el régimen heterosexual, como ya he señalado. La presupuesta y deseable heterosexualidad es considerada como una parte constitutiva de la construcción de las naciones latinoamericanas (Peterson, 2000; Luibhéid, 2002; 2005; Luibhéid y Cantú, 2005) sometidas a operaciones coloniales. Para reproducir una nación heterosexual existen dos aparatos institucionales importantes: la lesbofobia como un mecanismo de vigilancia externa y la lesbofobia internalizada como mecanismo disciplinario.

Tanto la lesbofobia internalizada y la lesbofobia externa están presentes en la mayoría de los relatos de estas ocho mujeres. La lesbofobia internalizada debe ser entendida como un mecanismo de disciplina de la mente hétero (Wittig, 1992) y de la 
heterosexualidad obligatoria: se constituye en el omnisciente vigilante en la distancia. Este mecanismo de vigilancia hace uso de diversas instituciones como la iglesia, la escuela y por supuesto, la familia, pero su éxito radica en que se encarna y actúa desde adentro de la mente y el cuerpo de las mujeres, cuya mayor desobediencia es negarse a cumplir con el papel de reproductoras de la familia y la nación. Considero que muchas de estas mujeres tratan de huir del espacio familiar/nacional en donde la vigilancia de la heterosexualidad obligatoria está garantizada en las esferas micropoliticas de sus vidas y que por eso, no es suficiente atribuir causas económicas para la migración; la migración es más bien una narración y una práctica entretejida de motivos que se encarnan en los cuerpos desde la operación de la llamada matriz de dominación (Hill Collins, 1998) en la que confluyen sistemas tales como raza, etnicidad, clase, edad, género, entre otros y sistemas de poder de los niveles micro, meso y macro.

\section{Construcción de sujeto: De la geopolitica a la vida cotidiana}

"Yo soy ambos, el Estado y la molécula"

Beatriz Preciado (2008, p. 104)

Para introducirnos en algunos de los hallazgos encontrados a partir del trabajo de campo realizado en Madrid durante el 2009, quisiera hacer un rápido esbozo de la construcción de sujeto de cada una de las entrevistadas, en especial en relación con los sistemas de heterosexualidad obligatoria, raza/racismo, etnicidad/xenofobia y clase.

En el siguiente cuadro muestro algunos aspectos del capital cultural de las mujeres entrevistadas, cruzados con sus actuales condiciones materiales de existencia y otros datos que permiten ver la singularidad de sus subjetividades: 


\begin{tabular}{|c|c|c|c|c|c|c|c|c|}
\hline \multicolumn{9}{|c|}{ CAPITAL CULTURAL DE LAS MUJERES ENTREVISTADAS } \\
\hline Seudónimo & Patricia & Alejandra & Milena & Juliana & Lina & Sonia & Tatiana & Clara \\
\hline $\begin{array}{l}\text { País de } \\
\text { origen }\end{array}$ & $\begin{array}{l}\text { Perú, } \\
\text { Argentina }\end{array}$ & Perú & Venezuela & Colombia & Colombia & Colombia & Ecuador & Ecuador \\
\hline $\begin{array}{l}\text { Nivel edu- } \\
\text { cativo }\end{array}$ & $\begin{array}{l}\text { Diplomada } \\
\text { en cinema- } \\
\text { tografia y } \\
\text { grado de } \\
\text { licenciada } \\
\text { en filosofia } \\
\text { en proceso } \\
\text { (España) }\end{array}$ & \begin{tabular}{|l|} 
Conoci- \\
mientos \\
empiricos \\
en elec- \\
tricidad \\
automotriz \\
(Perú)
\end{tabular} & $\begin{array}{l}\text { Abogada. } \\
\text { (Venezuela) } \\
\text { especia- } \\
\text { lizada, d } \\
\text { doctorado } \\
\text { en curso } \\
\text { (España) }\end{array}$ & $\begin{array}{l}\text { Ingeniera } \\
\text { de alimen- } \\
\text { tos, espe- } \\
\text { cialista en } \\
\text { gerencia y } \\
\text { mercadeo } \\
\text { (Colombia) } \\
\text { Postgrado } \\
\text { en tecno- } \\
\text { logias de } \\
\text { nutrición } \\
\text { en proceso } \\
\text { (España) }\end{array}$ & $\begin{array}{l}\text { Educación } \\
\text { secundaria } \\
\text { (Colombia) }\end{array}$ & $\begin{array}{l}\text { Trabaja- } \\
\text { dora social } \\
\text { (Colombia) } \\
\text { Postgra- } \\
\text { duada en } \\
\text { Género y } \\
\text { migración } \\
\text { (España) }\end{array}$ & $\begin{array}{l}\text { Educación } \\
\text { secundaria } \\
\text { (Ecuador) }\end{array}$ & $\begin{array}{l}\text { Educación } \\
\text { secundaria } \\
\text { incompleta } \\
\text { (Ecuador) }\end{array}$ \\
\hline $\begin{array}{l}\text { Conoci- } \\
\text { miento de } \\
\text { lenguas } \\
\text { distintas al } \\
\text { español }\end{array}$ & $\begin{array}{l}\text { Inglés, } \\
\text { alemán } \\
\text { (Perū), } \\
\text { aprendien- } \\
\text { do japonés } \\
\text { (España) }\end{array}$ & & $\begin{array}{l}\text { Conoci- } \\
\text { mientos de } \\
\text { Wayunai- } \\
\text { qui. } \\
\text { Inglés, } \\
\text { (Venezuela) } \\
\text { aprendien- } \\
\text { do alemán } \\
\text { (España) }\end{array}$ & $\begin{array}{l}\text { Conoci- } \\
\text { mientos } \\
\text { de inglés } \\
\text { (Colombia) } \\
\\
\end{array}$ & & & $\begin{array}{l}\text { Conoci- } \\
\text { mientos } \\
\text { de inglés } \\
\text { (Ecuador- } \\
\text { España) }\end{array}$ & \\
\hline $\begin{array}{l}\text { Ocupación } \\
\text { actual }\end{array}$ & $\begin{array}{l}\text { Desem- } \\
\text { pleada, } \\
\text { estudiante }\end{array}$ & \begin{tabular}{|l} 
Limpiadora \\
industrial \\
Depen- \\
dienta \\
en Mc \\
Donalds
\end{tabular} & $\begin{array}{l}\text { Estudian- } \\
\text { te/inves- } \\
\text { tigadora, } \\
\text { profesora } \\
\text { de niños. }\end{array}$ & $\begin{array}{l}\text { Cuidadora, } \\
\text { estudiante }\end{array}$ & Mesera & $\begin{array}{l}\text { Trabajado- } \\
\text { ra social }\end{array}$ & Cartera & Cuidadora \\
\hline $\begin{array}{l}\text { Ocua- } \\
\text { pación } \\
\text { anterior en } \\
\text { España }\end{array}$ & $\begin{array}{l}\text { Profesora } \\
\text { de lenguas }\end{array}$ & $\begin{array}{l}\text { Reparti- } \\
\text { dora }\end{array}$ & & & Cuidadora & & & $\begin{array}{l}\text { Camarera } \\
\text { de hotel }\end{array}$ \\
\hline $\begin{array}{l}\text { Estatus } \\
\text { legal }\end{array}$ & $\begin{array}{l}\text { Ciudadana } \\
\text { española } \\
\text { (por adop- } \\
\text { ciòn) }\end{array}$ & $\begin{array}{l}\text { Residente } \\
\text { legal }\end{array}$ & $\begin{array}{l}\text { Con auto- } \\
\text { rizaciòn de } \\
\text { estancia } \\
\text { por estu- } \\
\text { dios } \\
\end{array}$ & $\begin{array}{l}\text { Indocu- } \\
\text { mentada }\end{array}$ & $\begin{array}{l}\text { Ciudadana } \\
\text { española } \\
\text { (por adop- } \\
\text { ciòn) }\end{array}$ & \begin{tabular}{|l|} 
Residen- \\
te legal, \\
ciudadania \\
española \\
en proceso \\
\end{tabular} & $\begin{array}{l}\text { Residente } \\
\text { legal }\end{array}$ & $\begin{array}{l}\text { Residente } \\
\text { legal }\end{array}$ \\
\hline $\begin{array}{l}\text { Tiempo } \\
\text { total en } \\
\text { España }\end{array}$ & $\begin{array}{l}9 \text { años y } \\
\text { medio }\end{array}$ & 3 años & 5 años & $\begin{array}{l}3 \text { años, } 1 \\
\text { mes (inte- } \\
\text { rrumpido) }\end{array}$ & 10 años & 8 años & 10 años & $\begin{array}{l}5 \text { años } 6 \\
\text { meses }\end{array}$ \\
\hline $\begin{array}{l}\text { Ingresos } \\
\text { legales en } \\
\text { Euros }\end{array}$ & $\begin{array}{l}1007 \text { (sub- } \\
\text { sidio de } \\
\text { desempleo) }\end{array}$ & 1.200 & 360 & & 640 & 950 & $\begin{array}{l}840 \text { (más } \\
\text { comisio- } \\
\text { nes) }\end{array}$ & 600 \\
\hline $\begin{array}{l}\text { Ingresos } \\
\text { extrale- } \\
\text { gales en } \\
\text { Euros }\end{array}$ & No & No & $400-500$ & 350 & 400 & & & No \\
\hline $\begin{array}{l}\text { Otros } \\
\text { ingresos o } \\
\text { recursos }\end{array}$ & & & & Ahorros & & & Variable & \\
\hline $\begin{array}{l}\text { Condición } \\
\text { fisica } \\
\text { mental, } \\
\text { sensorial }\end{array}$ & -- & -- & $\begin{array}{l}\text { Problemas } \\
\text { de movili- } \\
\text { dad }\end{array}$ & -- & -- & -- & -- & -- \\
\hline
\end{tabular}


Uno de los aspectos más sobresalientes encontrados fue el hecho de que en la gran mayoría de los casos, la autodeterminación sexual tuvo lugar luego de la decisión de migrar. La manera y el tiempo en que este proceso -decididamente no lineal-ocurrió, dependió de cada experiencia particular. La migración ha influenciado la autodeterminación y viceversa.

No todas las mujeres entrevistadas se autonombran como lesbianas, no obstante en sus relatos es posible ver cómo este autonombramiento varia de acuerdo con los contextos sociales y también en algunos casos, un posible cambio en el autonombramiento parece predecible, como en el caso de Clara, que aunque recientemente se enamoró de una mujer también ecuatoriana -su mejor amiga en España-, sigue autonombrándose de manera indirecta como heterosexual, sin tener una conciencia clara del significado de esta categoría.

De las ocho mujeres entrevistadas solo cinco se autodefinen como lesbianas (Patricia, Alejandra, Sonia, Lina y Tatiana). El resto se autonombra de la siguiente manera: gay (Juliana); simplemente como mujer o persona (Milena); y heterosexual (Clara). Así, lesbiana como categoría de identidad resulta problemática para varias de ellas, quienes la cuestionan abiertamente. Por ejemplo, Juliana afirma que gay es una categoría que le resulta menos hiriente que lesbiana, ya que desde su punto de vista, lesbiana tiene una connotación peyorativa. Patricia y Milena sienten que la categoría lesbiana no logra incluir sus subjetividades en un todo complejo, sin embargo ambas terminan asumiendo este nombramiento, ya que durante sus relatos no encuentran otra palabra más adecuada. Pude observar además, que para ellas es muy importante aclarar que no quieren ser definidas solo a partir de los aspectos sexuales y emocionales de sus subjetividades.

Por otra parte, la narrativa de Alejandra hace que este análisis sea aún más complejo, pues aunque ella se identifica como lesbiana, no está segura de si identificarse como mujer o no. La etiqueta mujer también resulta problemática para la construcción de su subjetividad. Por lo tanto, para todas las entrevistadas, las categorias de lesbiana y mujer tienen significados inestables, intermitentes y polivalentes. En consecuencia, no podría decir que este trabajo trata exclusivamente sobre lesbianas migrantes, aunque es evidente que todas las entrevistadas están desplazadas en relación con la heterosexualidad obligatoria. Podría entonces afirmar que ellas, más que ser lesbianas, habitan la existencia lesbiana (Rich, 1984), que es un territorio incómodo y un 
campo en el que se despliegan diferentes estrategias de resistencia, muchas de ellas de carácter emocional: un lugar de frontera.

En cuanto a la racialización y el origen étnico de las entrevistadas, debo decir que este fue el aspecto que más incomodidad causó durante la entrevista. Parece que ninguna esperara ser interrogada al respecto y varias de ellas hicieron observaciones del tipo "esa es una pregunta muy extraña".

En las narraciones construidas con las entrevistadas es fácil ver que estas mujeres han incorporado formas sutiles de racismo que van en detrimento de ellas mismas y que algunas de las mujeres operan dichas formas para segregar a otras personas. Observé tanto un racismo fenotípico como uno más complejo vinculado a ideas sobre el prestigio (la elegancia), la belleza, o incluso la civilización y la modernidad, entre otros (véase Markowitz, 2001, pp. 394-405). Por otro lado, me encontré con que las ocho mujeres tienen discursos más transparentes en términos de su posición de clase, cuyas particularidades dadas por cada una de las trayectorias veremos en la última parte.

A partir de todo lo anterior resulta evidente la construcción de una serie de subjetividades complejas, plásticas e inestables, dada no solo a partir de las diversas identidades sexuales que se alteran en función del espacio y las circunstancias temporales, sino de otras señas de identidad dadas por la localización de cada una de las entrevistadas en las complejas redes de poder.

Estas ocho mujeres conforman un complejo panorama de subjetividades (habitus) signadas por diferentes circunstancias, las cuales no deben ser analizadas simplemente como una sumatoria de factores a favor o en contra, sino como una especie de sinergia, en muchas ocasiones negativa, si se me permite la contradicción de sentido, que se produce por la intersección de las diferentes circunstancias.

\section{La existencia lesbiana y las cadenas globales de cuidado}

Tomaré como punto de partida para la discusión la conocida premisa de Monique Wittig que señala que: "La categoría mujer sólo tiene sentido dentro del sistema económico y de pensamiento heterosexual. Las lesbianas no son mujeres, como no lo es ninguna mujer que no esté en una relación personal de dependencia con ningún hombre" (1992, p. 32). Con esta máxima, Wittig plantea que las lesbianas estarian por 
fuera de los sistemas de producción-reproducción dominados por los hombres y dentro de los cuales, para usar términos de Gayle Rubin (1996), las mujeres son presas de los hombres.

En este punto me parece importante hacer énfasis en que personalmente sostengo que la heterosexualidad obligatoria fue impuesta a través de la introducción del sistema sexo-género occidental a partir de las empresas colonizadoras en América Latina y el Caribe, entre otros, es lo que Lugones (2007) llama el sistema género moderno colonial. Hay literatura reveladora -desde las crónicas de los conquistadores europeos, pasando documentos de archivo, hasta estudios antropológicos o históricos- que muestra que han existido lo que podriamos llamar sistemas sexo-género divergentes del modelo Occidental, en diferentes épocas y lugares y que incluso hoy permanecen como forma de resistencia o descolonización (veáse Lucena Samoral, 1966; Wekker, 2006; Williams, 1992; Roscoe, 1988).

Retomando, la reproducción social sería entonces la base de la heterosexualidad entendida como sistema político-económico, ligado con proyectos como el colonialismo y la subsecuente colonialidad, la globalización, y el papel reproductivo -entendido de manera amplia y compleja- asignado a las mujeres, quizás el anclaje más opresivo de sus vidas.

Es por esto que la discusión sobre la heterosexualidad obligatoria no debe circunscribirse meramente a la esfera de las apetencias sexuales y afectivas, aunque por supuesto esta esfera hace parte del engranaje político de la vida de las mujeres. Como ya lo planteaba Rich (1984, pp. 637-638) el análisis de la heterosexualidad obligatoria no debe ser entendido como un apéndice temático de los estudios feministas o de los estudios acerca de los sistemas sexo-género (Rubin, 1996), sino como una categoría de análisis que atraviesa las relaciones de poder establecidas por el sistema sexo-género.

Si concebimos a las lesbianas como aquellas que se niegan a cumplir con este papel reproductivo, entonces deberiamos suponer que las lesbianas han logrado exceptuarse del sistema económico heterosexual que se sostiene sobre la plusvalia generada gracias al papel reproductivo de las mujeres (véase Carrasco, 2009).

Por las razones antes expuestas, Rich sostiene que la heterosexualidad obligatoria y la maternidad deben ser estudiadas como instituciones políticas "incluso o en particular por aquellas personas que sienten ser, desde su experiencia individual, las precursoras de 
una nueva forma de relación entre los sexos" (Rich, 1984, p. 637) Rich coincidiría con Wittig en la premisa inicial, pues sostiene que la existencia lesbiana ${ }^{10}$ es en sí misma un reto al orden doméstico de la dominación masculina dentro del cual se ha desarrollado una economía de los cuerpos y de las energías de las (Rich, 1984, p. 632).

Insisto entonces en la pregunta que orienta la presente discusión: ¿las migrantes lesbianas o mujeres con experiencias homoeróticas logran exceptuarse de dispositivos de reproducción tales como las cadenas globales de cuidado? Las cadenas globales de cuidado son un mecanismo que asegura la provisión de la energía emocional y física para las labores de cuidado cotidianas, bien sea de una manera primaria -es decir la que llevan a cabo las mujeres con su entorno familiar inmediato- o mediante el desplazamiento del cuidado hacia el mercado. Esto a su vez sucede gracias al déficit de cuidado de las sociedades industrializadas y postindustriales que ha tenido que ser suplido por mujeres de la clase trabajadora, mujeres rurales o en la gran mayoría de los casos por mujeres inmigrantes, lo que a su vez genera un déficit de cuidado en estos segmentos sociales o en países proveedores de mujeres migrantes, lo que debe ser atendido por trabajo de cuidado no remunerado o en condiciones muy precarias, asumido por mujeres de clases bajas, en relaciones familiares de explotación y de países que ocupan el lugar de la geopolítica llamado sur global.

Se produce entonces lo que se llama un emotional surplus value o plusvalía emocional, que es el valor emocional agregado que proveen las mujeres contratadas, la gran mayoría de ellas migrantes, en condiciones muchas veces inferiores a las normales dentro del mercado laboral, lo que redunda en un mercado globalizado del cuidado (Hochschild, 2000).

Entiendo por globalización, una serie de desplazamientos de población a través de fronteras nacionales que tienen lugar en un panorama de pugna cultural o movimiento entre la homogenización y la heterogenización cultural (Appadurai, 1990). Un "proceso abierto y contradictorio que conlleva la reestructuración del sistema económico y las estructuras regulatorias keynesianas, articulados entre sí mediante los estados Nación" (Young, 2002, p. 49; Arango, 2004) y de expansión de capitales.

10 "Yo elegi usar las expresiones existencia lesbiana y continuum lésbico porque la palabra lesbianismo tiene un aura clínica limitante. Con la noción "Existencia lesbiana" sugiero tanto el hecho histórico de la presencia de las lesbianas como nuestra continua creación del significado de esa existencia" (Rich, 1984, p. 189. Traducción de la autora). 
La globalización, como una política de expansión del capital, necesita de la plusvalía generada por las mujeres en la esfera doméstica. Al mismo tiempo, el proyecto de la globalización necesita mantener inserta dentro del mercado de trabajo reconocido la fuerza de trabajo de las mujeres, lo que termina por hacer que algunas mujeres bien remuneradas deleguen el cuidado de hijos, ancianos, personas con discapacidad y enfermos a otras mujeres. Esto teniendo en cuenta que el cuidado no es asumido como un asunto público, ni siquiera en los Estados de bienestar y tampoco está bien avaluado en el trabajo mercantilizado.

La idea de mujer como cuidadora natural está ligada de manera intrínseca con la explotación de las mujeres que producen plusvalía no reconocida, plusvalía tanto económica como emocional (Jónasdóttir, 1993; Hochschild, 2000). Semejante noción de mujer descansa en la reproducción de la heterosexualidad obligatoria, que después de todo y gracias a las empresas coloniales, se ha convertido en una institución casi universal con excepciones aún poco documentadas.

Rubin (1996, p. 114) establece que la división sexual del trabajo podría entenderse como una especie de tabú que impide la igualdad entre hombres y mujeres; divide el género en dos categorias opuestas llevando a los extremos las diferencias biológicas y en consecuencia, da origen al sistema sexo-género. Además esta división puede ser considerada un tabú contra los arreglos sexuales que no acontecen entre un varón y una mujer, lo que da bases para la institucionalización del matrimonio o el intercambio heterosexual. De esta manera, el concepto de Rubin (1996, p. 96) tráfico de mujeres resulta útil para comprender cómo y porqué las mujeres migrantes son ubicadas en el mercado global y cómo terminan siendo redosmesticadas.

Es sabido que a menudo mujeres migrantes de los llamados países en vías de desarrollo son reinsertadas en cadenas de cuidado, las que definen su situación en ciudades globales y circuitos de supervivencia "que han emergido en respuesta a la cada vez más profunda miseria del sur global" (Sassen, 2004, p. 255; Arango 2004). Aunque la mirada de Sassen no es un análisis reduccionista sino más bien estructural económico, es importante reconocer -como anota Kofman (2000, p. 138), al criticar la perspectiva de Sassen-, que dentro del flujo migratorio de mujeres hay un incremento de mujeres cualificadas migrantes.

Muchas mujeres deciden migrar porque el mercado internacional de trabajo les ofrece un nuevo lugar en la esfera del trabajo doméstica y 
muchas de ellas, aunque cualificadas, aceptan formas de subempleo. La migración como desplazamiento de fuerza de trabajo es una de las características más importantes de la globalización. La globalización en sentido literal y figurativo implica desplazamiento, desenclave.

Pat Thane afirma que "todos los Estados modernos son ahora Estados de bienestar" (2002, p. 27) y que sin embargo, estos Estados no son siempre los únicos proveedores frente a la demanda social, por lo que como respuesta aparece a lo que la autora llama los sistemas de bienestar o economias mixtas de bienestar que son sistemas mixtos en los cuales el papel del Estado se ve complementado mediante el soporte de la familia y del sector comercial privado. Esto significa que la familia es funcional a Estados que consideran asuntos como el cuidado, como pertenecientes a la esfera de lo privado y que a su vez, estos Estados son funcionales a la globalización, en donde primordialmente las mujeres sostienen la economía del cuidado, una parte oculta de la producción mundial y la reproducción misma del sistema (mediante la reproducción de la fuerza de trabajo, de la procreación y trasmisión cultural).

Las lesbianas -o las mujeres que no cumplen a pie juntilla los preceptos de la heterosexualidad obligatoria- a pesar de su resistencia frente a dicha norma, terminan por ser reinsertadas en las cadenas de cuidado a través del precario mercado laboral en el que las migrantes son situadas.

Aun cuando vivir una existencia lesbiana pueda significar estar fuera del campo de la dominación masculina, encontré que la mayoría de las ocho mujeres entrevistadas han sido relegadas en algún momento de su historia personal, al rol de cuidadoras, incluso teniendo algunas de ellas cualificación suficiente para desempeñar otros trabajos, tal y como sucede con una gran mayoría de mujeres filipinas (Parreñas, 2001). Esto indica que la heterosexualidad obligatoria como régimen político y económico opera más allá de las prácticas eróticas o afectivas determinadas por una u otra orientación del deseo.

Algunas de las mujeres entrevistadas, (véase cuadro 1) Juliana y Lina, se ven reinsertadas en las cadenas globales de cuidado después de su decisión de migrar, es decir, los avances legales en el reconocimiento de parejas del mismo sexo en España o en políticas dirigidas a las mujeres no inciden en absoluto en una situación que incluso ellas habian evadido en sus países de origen. 
Otras como Alejandra, Clara o Tatiana tomaron la decisión de migrar porque sus familias o ellas mismas ven en la migración una forma de cuidar de sus familias enviando remesas. La gran mayoría de ellas desempeñaban el papel de cuidadoras-proveedoras en mayor o menor medida dentro de sus familias, por lo que con la decisión de migrar, algunas buscan deshacerse de ese papel o por el contrario, reforzar el papel de proveedoras.

Sonia, Patricia y Milena -que llegaron a España para estudiar y en condiciones materiales suficientes, y lograron con una permanencia de cerca de diez años conseguir la ciudadanía española- son las únicas de las entrevistadas que no han tenido que trabajar como cuidadoras o como mano de obra no-cualificada. De ellas tres, solamente Sonia ha tenido un trabajo bien remunerado y con todas las prestaciones legales, esto gracias a que con sus compañeras de migración todas ellas autodefinidas como lesbianas feministas-, logró establecer una asociación dedicada a trabajar en asuntos de género y migración, la que les permitió generar una fuente de autoempleo. Esta red también fue determinante en el proceso de autodefinición como lesbiana que Sonia aplazó durante toda su vida en Colombia.

Juliana, graduada en ingeniería nutricional, llegó a España con sus ahorros esperando conseguir un buen trabajo y una mejor calidad de vida a la que tenía en Colombia. Sin embargo, ella se ha visto obligada a trabajar como cuidadora mientras adelanta estudios de especialización, aunque como indocumentada. Por estas circunstancias, Juliana vive con su familia, lo que ha afectado su relación de pareja. En el caso de Juliana es claro que todos los costos de su migración, tanto materiales como emocionales, recaen sobre ella y su familia: siendo migrante indocumentada, Juliana no está en relación con ningún sistema estatal, ni el de origen, ni el de llegada.

Por su parte Alejandra, viviendo aún en Perú, compró un contrato como peluquera por 6.000 euros con el fin de obtener una visa de trabajo en España. Sin embargo, ella no estaba cualificada para esa labor, así que cuando llegó a España, se dio cuenta de que la visa obtenida no le permitiría acceder a un trabajo para el que ella estuviera cualificada. Alejandra migró a España con el propósito de ahorrar dinero para lograr una inseminación artificial con su pareja, quien para el momento de la entrevista, aún vivía en Perú. Ella relata cómo esta relación de pareja -hace ya un par de años-está en crisis, dado que su compañera dio a luz a un niño y en la actualidad, vive con su pareja masculina. En el relato es evidente que ella ha tenido que enfrentar la 
heteronormatividad constante dentro de su familia y pareja desde que era una niña.

Es posible ver que no solo la lesbofobia como mecanismo de control social -y que funciona como mecanismo disciplinario (lesbofobia internalizada) o como mecanismo externo, (lesbofobia social) - obstaculiza la existencia lesbiana de estas mujeres, sino también las condiciones materiales de existencia, tanto en sus paises de origen como en España.

De las ocho entrevistadas, Clara es tal vez quien ha tenido que enfrentar las condiciones materiales más adversas, tanto en Ecuador como en España. Clara narró cómo se vio obligada a dejar su primer trabajo como cuidadora en España, pues aunque estaba relativamente bien remunerada, recibía constante maltrato por parte de su empleadora, además era un empleo que demandaba su disponibilidad veinticuatro horas al dia, todos los dias, como sucede normalmente con este tipo de empleos no suficientemente regulados por el Estado. En la actualidad, cuida de una niña y recibe un salario de 600 euros, suma inferior al salario mínimo legal vigente en España. Ella justifica la baja remuneración diciendo que "en realidad no tiene que hacer nada", lo que revela una preconcepción acerca del cuidado como si no fuese un trabajo propiamente dicho.

Por su parte Tatiana, que en la actualidad trabaja como repartidora de correo -pero que tuvo que trabajar como cuidadora a su llegada-, dice que su experiencia no fue dificil, dado que "era considerada como parte de la familia" gracias a que era más paciente que los propios parientes de la anciana a la que cuidaba.

En las narraciones de Clara y Tatiana vemos de forma clara cómo funciona la plusvalía emocional, que caracteriza en parte a las cadenas de cuidado. Esta plusvalía se sostiene sobre la preconcepción de las mujeres como cuidadoras naturales, por lo que el trabajo de cuidado se ve como vocación que no implica esfuerzo y mientras es naturalizado, pareciera que tiende a desestimarse una intervención reguladora por parte del Estado y de la sociedad.

Lina, siendo comerciante de arte en Colombia, también tuvo que trabajar como cuidadora durante los primeros años de su estancia en España. En su relato, Lina muestra una permanente conexión emocional con la familia para la que trabajaba, especialmente con los dos niños a los que cuidaba. Dado que se trataba de una familia influyente de Madrid y en España, ella pudo regularizar su situación legal mucho 
más fácilmente de lo usual, gracias a un favor de sus empleadores, que en todo caso requerian de sus servicios.

Como he mostrado, Lina, Tatiana y Clara manifiestan su proximidad afectiva con las personas a su cuidado. La energía emocional que ellas han dedicado ha sido retribuida con demostraciones afectivas, pagos extras o ayudas personales que son percibidas como premios y no como derechos laborales. Esto da pie a que se establezca una relación regulada por la lógica privada, en la que el Estado deja de cumplir con su papel social como garante de derechos de las personas. Resulta paradójico que muchas de estas mujeres tengan que destinar sus energías a reproducir familias ajenas, cuando al mismo tiempo tienen que enfrentar una lesbofobia pertinaz en sus familias de origen, cuando se les ha negado históricamente el derecho social a tener una familia propia.

Asimismo es paradójico que tengan que ser cuidadoras cuando varias de ellas no contemplan la maternidad o el establecimiento de una familia dentro de sus proyectos de vida. Resulta paradójico que contribuyan al soporte de dos Estados, el de su país de origen y el de España, que no les conceden una titularidad plena de derechos, bien sea por cuestiones raciales, étnicas, sexuales o de origen nacional.

De esta manera las mujeres y en particular las lesbianas, son aún "presas de los hombres" (Rubin, 1996) a través de un sistema politicoeconómico que las condena a su propia reproducción y que les impone la institución de la heterosexualidad obligatoria más allá de su orientación del deseo.

No obstante, es importante subrayar que en todas las narraciones la migración es vista como la posibilidad de ganar autonomía, la que se alcanza si se cumplen dos premisas: separarse de la familia que actúa como mecanismo disciplinario de control social, en lo que coincido con las conclusiones del estudio de Acosta (2009), y ganando autonomía económica.

Sin embargo, debo anotar que algunas de las mujeres no logran separarse del todo de sus familias, incluso porque algunas, como Tatiana y Juliana, conviven con algunos parientes o porque algunos familiares han migrado, aunque de manera independiente y permanecen en Madrid. También porque las colonias nacionales siguen siendo espacios de contención -en el sentido positivo y negativo de la palabra-, para estas mujeres. 
Por otro lado, la lesbofobia internalizada sigue actuando como una especie de vigilante en la distancia, como se puede constatar en la entrevista con Alejandra, quien manifiesta en varias ocasiones su desacuerdo con las manifestaciones de afecto en público entre parejas del mismo sexo que cada vez se ven con más frecuencia en ciertas zonas de Madrid.

\section{La migración: un lugar de dislocación, una borderland ${ }^{11}$}

La extranjera

Hablo, con dejo de otros mares. $Y$ ya no sé qué arenas guardarán secretas aquel pequeño puñado de historias que fui, tan lejos de aqui Hoy, tu cuerpo es quien me enseña a vivir $Y$ desde que me abrazas Desde que me besas No soy aquella que llega y que piensa distancias Tu vida también es mi país

Liliana Felipe ${ }^{12}$

La localización de estas mujeres que no se ajustan a la heterosexualidad prescriptiva en las redes de poder deviene en últimas en una situación de dislocación, es decir, de suspensión en el espacio social. No obstante, al mismo tiempo, ellas despliegan una serie de estrategias individuales y colectivas, algunas de ellas basadas en su resistencia al régimen heterosexual, aunque esto es relativo, pues como he intentado mostrar, este régimen tiene una eficacia estructural y estructurante que sobrepasa las elecciones sobre la orientación del deseo y mantiene su operación en distintos niveles de poder que hace a veces inaprensibles los mecanismos de tal institución.

La migración se configura tanto como posibilidad de hacer resistencia dentro de las redes de poder y como dislocación. La migración exige poner en práctica diversas estrategias con el fin de cruzar las barreras sociales y legales que imponen los países de origen y acogida.

${ }^{11}$ Para otra interpretación de la noción borderland en cuanto a la migración de mujeres lesbianas véase Acosta (2009).

${ }_{12}$ Liliana Felipe es una compositora argentina, artista performativa y cantante, que vive en el exilio en México con su compañera y "esposa”, Jesusa Rodríguez Gamma, dramaturga. 
La migración es un desplazamiento constante, desarraigo, ciudadanía en suspensión.

El borderland (Anzaldúa,1987) es un lugar simbólico y material que representa no solo una división, sino también una posición material de los sujetos en una red de poder en tanto sujetos sujetados o sujetos subjetivos. Creo que la relevancia del concepto borderland descansa en su significado geopolítico así como en la denotación de la experiencia individual, grupal y local, es decir, en el entendimiento metafórico implícito del movimiento y de la yuxtaposición de los diferentes niveles de poder en la experiencia subjetiva.

En este lugar llamado borderland, las estructuras sociales de clase, étnico-raciales y heterocentradas, tanto del país de origen como del de acogida, fomentan una existencia fragmentada de lesbianas migrantes, muchas de ellas racializadas o situadas étnicamente a partir del proceso migratorio. Al mismo tiempo, este lugar les permite un escape de sus propias culturas que, parafraseando a Anzaldúa (1987, pp. 15-23), "las han traicionado".

Muchas veces estas mujeres han tenido que afrontar aislamiento emocional, responsabilidades frente a sus propias familias y familias ajenas; desempleo o subempleo; xenofobia y racismo sutil, ambos articulados por medio de una colonialidad prevalente; lesbofobia y misoginia producto del régimen heterosexual reinante -en distintos grados en sus países de origen y en España- y exclusión por sus corporalidades singulares (por ejemplo, por tener una discapacidad o una determinada forma de gestualidad, una cierta apariencia).

Sus condiciones personales de existencia y cómo ellas experimentan sus vidas en términos emocionales y sexuales están atravesados por los niveles geopolítico, biopolítico y micropolítico del poder, los que en ocasiones, actúan como una afilada hoja que cruza y fragmenta sus vidas y sus subjetividades.

Sin embargo, al final para resistir esta fragmentación del ser, para resistir ese estar a la deriva, ellas hacen uso de estrategias emocionales, financieras y de conocimiento y ponen en juego estrategias individuales y colectivas para vencer el desarraigo y las condiciones precarias en que las deja su situación de suspensión. 


\section{Referencias}

Acosta; K. (2009). Lesbianas in the Borderlands: Shifting Identities and Imagined Communities. Gender and Society, 22 (5), 639-659. Disponible en: http://gas. sagepub.com.

Anzaldúa, G. (1987). Borderlands La frontera. San Francisco: Aunt Lute Book Company.

Appadurai, A. (1990). Disjuncture and Difference in the Global Cultural Economy. Theory, Culture \& Society, 7 (2-3), 295-310.

Arango, L. G. (2004, junio). Mujeres, trabajo y tecnología en tiempos globalizados. Series Cuadernos CES, 5 3-17.

Bettio, F., Simonazzi, A. y Villa, P. (2006). Change in care regimes and female migration: the 'care drain' in the Mediterranean. Journal of European Social Policy, 16 (3), 271-85.

Bourdieu, P. (2000). Cuestiones de sociología (Martín Criado, E. Trad.). Madrid: Ediciones Istmo.

Carrasco Bengoa, C. (2009). Mujeres, sostenibilidad y deuda social. Revista de educación, (1), 169-191.

Castro-Gómez, S. (2002). Michel Foucault y la colonialidad del poder. Bogotá: Universidad Javeriana, Instituto Pensar. Disponible en: http://amauta.upra. edu/vol4investigacion/vol_4_Michel_Foucault_y_la_Colonialidad_del_Poder.pdf

Castro-Gómez, S. (2004). Latinoamericanismo, modernidad, globalización prolegómenos a una crítica poscolonial de la razón. En Globalización y diversidad cultural: una mirada desde América Latina (pp. 118-149). Lecturas contemporáneas, $\mathrm{N}^{\circ} 2$, Lima: Instituto de estudios peruanos, IEP.

Chaves, M. y Zambrano, M. (2006, abril). From blanqueamiento to reindigenización: Paradoxes of mestizaje and multiculturalism in contemporary Colombia. Revista Europea de Estudios Latinoamericanos y del Caribe, (80), 5-23.

CIS. (2007). Estudio 2.681. Barómetro social de marzo de 2007. Disponible en: http://www.cis.es/cis/opencm/ES/2_barometros/depositados.jsp

CIS (2007). Estudio CIS $N^{o}$ 2.745. Discriminaciones y su percepción. Disponible en: http://www.cis.es/cis/opencm/ES/1_encuestas/estudios/ver. jsp?estudio $=8940$. Madrid

CIS. (2009a). Estudio 2.788. Barómetro social de febrero de 2009. Disponible en: http://www.cis.es/cis/opencm/ES/2_barometros/depositados.jsp

CIS. (2009b). Estudio 2.794 Barómetro social de marzo de 2009. Disponible en: http://www.cis.es/cis/opencms/ES/2_barometros/avances.html

Colectivo Ioé y CIS (2007, diciembre). Interpretaciones de la condición migrante: Exploración de los discursos de la población inmigrada en España. Disponible en: http://www.colectivoioe.org/ficheros_externos/La\%20condicion\%20 
migrante\%20en\%20Espana.\%20Posiciones\%20basicas\%20en\%20torno\%20 a\%20la\%20ciudadania_La\%20condicion\%20migrante_Articulo\%20papeles.pdf

Esguerra Muelle, C. (2006). Lo innominado, lo innominable y el nombramiento. Categorización y existencia social de sujetos sexuales. En De mujeres, hombres y otras ficciones: Género y sexualidad en América Latina (pp.247-277). Lecturas CES, Facultad de Ciencias Humanas - GESSAM. Bogotá: Grupo TM Editores.

Esguerra Muelle, C. (2009). Book Review De la cama a la calle: perspectivas teóricas lésbico-feministas [From the Bed to the Street: Lesbian-Feminist Theoretical Perspectives] by Jules Falquet (2006). Graduate Journal of Social Science, 6, 45-148. Disponible en: http://www.gjss.org/

Falquet, J. (2006). De la cama a la calle. Bogotá: Brecha lésbica.

Folgueiras Bertomeu, P. (2005). De la tolerancia al reconocimiento: Programa de formación para una ciudadanía intercultural. Tesis doctoral. Barcelona: Universidad de Barcelona, Facultad de pedagogía..

Hill Collins, P. (1998). La política del pensamiento feminista negro. En: Navarro, M. y Stimpson, C. (Comps.) ¿Qué son los estudios de mujeres? (pp. 253-312). Argentina: Fondo de cultura económica.

Hochschild, A. (2000). Global care chains and emotional surplus value. En Hutton W. y Giddens, A. (Eds.). On the edge: Living with global capitalism (pp. 130-146). London: Jonathan Cape.

INE. (2008). National Immigrant Survey 2007. Disponible en: http://www.ine. es $/$ jaxi $/$ menu.do?type $=$ pcaxis $\&$ path $=\% 2 F t 20 \% 2 F p 319 \&$ file $=$ inebase $\& \mathrm{~L}$

Jónasdóttir, A. (1993). El poder del amor ¿Le importa el sexo a la democracia? Madrid: Cátedra.

Kofman, E. (2000). Beyond a reductionist analysis of female migrants in global european cities: The unskilled, deskilled and professional. En Marchand, M. H. y Sisson Runyan, A. (Eds.). Gender and Global Restructuring: Sightings, Sites and Resistances (pp. 129-139). London and New York: Routledge.

Lucena Samoral, M. (1966). Bardaje entre una tribu guahibo del Tomo. Revista colombiana de antropología, 14, 261-66.

Lugones, M. (2007, invierno). Heterosexualism and the Colonial/Modern Gender System. Hypatia, 22 (1), 186-209

Luibhéid, E. (2002). Entry denied: Controlling sexuality at the border. Minneapolis: University of Minnesota Press.

Luibhéid, E. (2005). Heteronormativity responsibility and neoliberal governance. En Epps, B., Valens, K. y Johnson González, B. (Eds.). Passing lines: Sexuality and immigration. Cambridge, MA: Harvard University Press.

Luibhéid, E. y Cantú, L. (2005). Queer Migrations: Sexuality, U.S. Citizenship and Border Crossing, Minneapolis: University of Minnesota Press. 
Markowitz, S. (2001). Pelvic politics: Sexual dimorphism and racial difference. Signs, 26 (2), $389-414$.

Parreñas, R. (2001). Transgressing the Nation-State: the partial citizenship and 'imagined (global) community' of migrant Filipina domestic workers. Signs, 26 (4), 1129-1154.

Peterson, S. (2000). Sexing political identities/nationalism as heterosexism. En Nilssons, R. y Tétreault, M. A. (Eds.). Women, States and Nationalism. At Home in the Nation? (pp. 54-80). London and New York: Routledge.

Pichardo Galán, J. I. (2004). Same-sex couples in Spain. Historical, contextual and symbolic factors. En Digoix, M. y Festy, P. (Eds.). Same-sex couples, samesex partnerships \& homosexual marriages: A Focus on cross-national differentials (pp. 159-174). Documents de travail: Institut national d'études démographiques. Disponible en: http://www.ined.fr

Pisano, M. (2004). Julia, quiero que seas feliz. Santiago de Chile: Surada.

Precarias a la deriva (2003). A la deriva por los circuitos de la precariedad femenina., Madrid: Traficantes de sueños.

Preciado, B. (2008). Testo Yonky. Madrid: Espasa Calpe.

Rich, A. (1984). Compulsory heterosexuality and lesbian existence. En Desire: The Politics of Sexuality (pp. 130-141). London: Virago.

Roscoe, W. (1988). Strange country this: Images of Berdaches and Warrior Women. En Living the Spirit: A Gay American Indian Anthology (pp. 48-76). Nueva York: St. Martins Press.

Rubin, G. (1996). El tráfico de mujeres: notas sobre la economía política del sexo. En Lamas, M. (Ed.). El género la construcción cultural de la diferencia sexual (pp. 35-96). México, D.F.: PUEG.

Sassen, S. (2004). Global Cities and Survival Circuits. En Ehrenreich, B. y Hochschild, R. A. (Eds.) Global Woman: Nannies, Maids, and Sex Workers in the New Economy (pp. 254-274). New York: Owl Books.

Stepan, N. L. (1991). The hour of eugenics: Race, gender, and nation in Latin America. Cornell: Ithaca.

Thane, P. (2002). Histories of the Welfare State. En Jensen, H. (Ed.). The Welfare State: Past, Present, Future (pp. 27-40). Pisa: Università di Pisa.

Waaldijk, K. (2004). Levels of legal consequences of marriage, cohabitation and registered partnership in nine European countries. En Digoix, M. y Festy, P. (Eds.). Same-sex couples, same-sex partnerships \& homosexual marriages: A Focus on cross-national differentials (pp. 159-174). France: Documents de travail : Institut national d'études démographiques,. Disponible en : http:// www.ined.fr 
Wallerstein, I. (1974). The Modern World-System. New York: Academic Press.

Wekker, G. (2006). The Politics of Passion. Women's sexual Culture in the AfroSurinamese Diaspora. New York: Columbia University Press.

Williams, W. (1992). The Spirit and the Flesh, Sexual Diversity in the American Indian Culture. Boston: Beacon Press.

Wittig, M. (1992). Straight Mind and Other Essays. Boston: Beacon Press.

Young, B. (2002). Globalization and Gender: A European Perspective. En BeckerSchmidt, R. Gender and Work in Transition: Globalization in Western, Middle and Eastern Europe (49-81). Opladen: Leske y Budrich.

\section{Cómo citar este artículo}

Esguerra, C. (2014). Dislocación y borderland: Una mirada oblicua desde el feminismo descolonial al entramado migración, régimen heterosexual, (pos) colonialidad y globalización. Universitas Humanística, 78, 137-161. http:// dx.doi.org/ 10.11144/Javeriana.UH78.dbmo 